\title{
Building Flexible Organizations for Fast-moving Markets
}

Henk W. Volberda

$\mathbf{H}$ or chang and stability? How do they promote order and control, while having to respond, innovate and learn? Notwithstanding these provocative questions, most of the literature in strategic management is still rooted in stability, not change. ${ }^{1}$ When environmental changes become increasingly undefined, fastmoving and numerous, it is risky to rely upon conventional strategic management approaches. Therefore, some researchers in strategic management considered organizational flexibility as a strategic option. $^{2-5}$

Ir. this article we will further elaborate the flexibilily option. We will show that flexibility is a way of increasing control in highly turbulent environments. In this approach flexibility is treated as a two-dimensional concept. First, flexibility is perceived to be a managerial task. In this connection, the concern is with the 'control capacity' of the management. Second, flexibility is perceived as an organization design task. The concern here is with the 'controllability' of the organization under different conditions.

On the basis of these two dimensions, a rich typology of organizational forms is developed, consisting of the rigid, the planned, the flexible and the chaotic mode. Furthermore, different trajectories of organizational failure and success are derived from this typology. Subsequently, the article describes a method for diagnosing organizational flexibility and guiding the transition process, the Flexibility Audit \& Redesign (FAR) method. The method was applied in an empirical study of three different organizational units operating in different, changing environments.
Ey considering flexibility as a valuable strategic option in turbulent environments, this article distinguishes four types of effective response to strategle change. From this typology different trajectories of revitalization are derived. On the basis of this typology the article describes a mothod for dlagnosing organizational flexibility and guiding the transition process, the Flexibility Audit Q Redesign (FAR) mothod. This method was applied successfully within the Dutch Postbank NV, Philips Semiconductors and the Dutch National Gas Corporation. The findings suggest that a viable corporation has to oscillate between 'planned' and 'flexible' forms. In this process of change, the corporation has to prevent itself from overshooting and becoming extremely rigid or chaotic. (1997 Elsevier Science Ltd

\section{From Planning Strategies Towards Flexibility Strategies}

Surprisingly enough, it was Ansoff, ${ }^{6}$ one of the founders of the planning approach in strategy, who suggested that the nature of environmental change was altering and giving rise to strategic surprises. According to Ansoff, the planning concept of strategy had to be re-examined. The basic effect of uncertainty is that it limits the ability of the organization to pre-plan or make decisions about activities in advance of their execution. The more uncertain the situation, the more an organization will need flexibility as a complement 
to planning. ${ }^{4}$ Therefore, Ansoff asserted that in these situations the use of planning strategies would be increasingly supplemented and sometimes replaced by preparedness or flexible strategies.

This loosening of the planning school in strategic management contributed substantially to the concept of organizational flexibility. Organizational flexibility is considered as a strategic option in situations in which anticipation is impossible and strategic surprise likely.

\section{Exploring the Flexibility Option}

A clearer understanding of the flexibility option can be derived hased on some insights drawn from systems theory of control. ${ }^{7} \mathrm{~A}$ firm is 'under control' when for each competitive change there is a corresponding managerial capability and firm response. In stable environments flexibility is not a serious strategic option to achieve control. A stable environment in which there is infrequent and predictable change increases the likelihood that the critical variables can be identified and allows plans to be developed. However, in extremely turbulent environments in which change is frequent and radical, organizations choosing the planning option may become easily adrift. A better alternative to achieve control is the flexibility option which requires high responsiveness (controllability) of the organization and sufficient managerial capabilities (control capability of management). The flexibility of an organization is the outcome of an interaction between 1. the controllability or responsiveness of the organization and 2, the dynamic control capacity of management. This inter- action is such that each must be in balance. The two parts are complementary, not substilutes. More controllability does not compensate for less capacity.

So flexibility is a function of the interaction of two sets of variables. In terms of management and organization, flexibility is a function of the control capability of the management and the changeability of the organization.

We can see this duality in two separate tasks (see Figure 1). First, flexibility is perceived to be a managerial task. Can managers respond at the right time in the right way? In this connection, the concern is with the managerial capabilities that endow the firm with flexibility, e.g. manufacturing flexibility to expand the number of products the firm can profitably offer to the market or innovation flexibility to reduce the response time for bringing new products to the market. Socond, flexibility is perceived as an organization design task. Can the organization react at the right time in the directed way? The concern here is with the 'controllability' or changeability of the organization which involves the creation of the right conditions to foster flexibility. For instance, manufacturing flexibility requires a technology with multipurpose machinery, universal equipment and an extensive operational production repertoire. ${ }^{8}$ In the same way, innovation flexibility requires a structure of multi-functional teams, few hierarchical levcls and few process regulations. ${ }^{9}$

\section{The Managerial Task: Increasing the Flexibility Repertoire}

As a management task, flexibility is concerned with the creation or promotion of the organization's con-

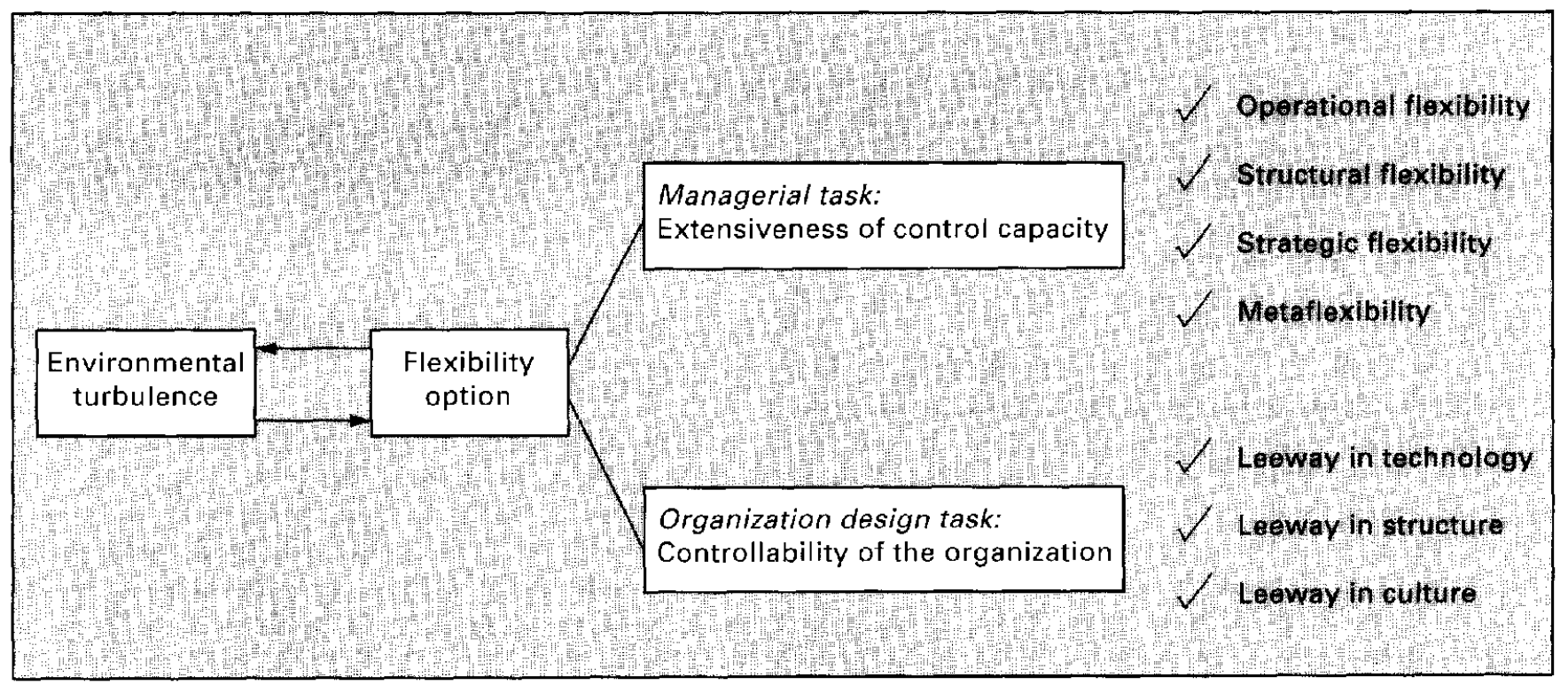

FIGURE 1. Developing flexibility: the managerial and organization design challenge. 
TABLE 1. Examples of internal and external types of flexibility

\begin{tabular}{|c|c|c|}
\hline \multirow{2}{*}{$\begin{array}{l}\text { Capacity for } \\
\text { manoeuver }\end{array}$} & \multicolumn{2}{|l|}{ Type of flexibility } \\
\hline & Internal & External \\
\hline Routine & $\begin{array}{l}\text { Internal operational flexibility } \\
\text { Variation of production volume } \\
\text { Building up inventories } \\
\text { Use of crash teams }\end{array}$ & $\begin{array}{l}\text { External operational flexibility } \\
\text { Use of temporary labour } \\
\text { Multisourcing } \\
\text { Reserving capacity with suppliers }\end{array}$ \\
\hline Adaptive & $\begin{array}{l}\text { Internal structural flexibility } \\
\text { Creating multifunctional teams } \\
\text { Changing managerial roles } \\
\text { Alterations in control systems }\end{array}$ & $\begin{array}{l}\text { External structural flexibility } \\
\text { Purchasing components from suppliers with a short } \\
\text { delivery time (JIT) } \\
\text { Purchasing subassemblies from suppliers } \\
\text { (co-makership) } \\
\text { Developing subcomponents together with suppliers } \\
\text { (co-design) }\end{array}$ \\
\hline Strategic & $\begin{array}{l}\text { Internal strategic flexibility } \\
\text { Dismantling current strategy } \\
\text { Applying new technologies } \\
\text { Fundamentally renewing products }\end{array}$ & $\begin{array}{l}\text { External strategic flexibility } \\
\text { Creating new product market combinations } \\
\text { Using market power to deter entry and control } \\
\text { competitors } \\
\text { Engaging in political activites to counteract trade } \\
\text { regulations }\end{array}$ \\
\hline
\end{tabular}

trol capacity, especially in situations of unexpected disturbance. The management task is manifested in the organization's 'flexibility mix'. This refers to the repertoire of flexibility increasing capabilities which an organization possesses, and the rapidity with which an organization can activate these capabilities. The flexibility mix consists of three types of flexibility (see Table 1): operational flexibility, structural flexibility and strategic flexibility. For each of these three types of flexibility a distinction can be made between internal and external flexibility. ${ }^{3}$ Internal flexibility is defined as management's capability to adapt to the demands of the environment. External flexibility is defined as management's capability to influence the environment so that the firm becomes less vulnerable to environmental changes.

Operational flexibility. Operational flexibility or routine manoeuvering capacity consists of routines that are based upon existing structures or goals of the organization. It is the most common type of flexibility and relates to the volume of activities rather than the kinds of activities undertaken within the organization. These routines are primarily directed at the operational activities and are reactive in nature. Operational flexibility provides rapid response to changes that are familiar. Such changes typically lead to temporary, short-term fluctuation in the firm's level of activity. Even though the variety in the environment may be high, the sort of combinations is reasonably predictable so that the organization, on the basis of experience and extrapolation, is able to develop certain routines to reduce this uncertainty. Examples of internal operational flexibility are the variation of production volume in the organization, the building up of inventories and the maintenance of excess capacity in terms of financial resources. External operational flexibility can be achieved by contracting out of certain peripheral activities, using temporary labour to adjust the size of the workforce or obtaining resources from more than one supplier.

Structural flexibility. Structural flexibility or adaptive manoeuvering capacity refers to the capacity of the management to adapt its decision and communication processes within a given structure as well as the rapidity by which this can be accomplished. ${ }^{10}$ When faced with revolutionary changes, management needs great internal structural flexibility or intraorganizational leeway to facilitate the renewal or transformation of current processes. Examples of internal structural flexibility are horizontal or vertical job enlargement, the creation of small production units or work cells within a production line, changes in organizational responsibilities, alterations in control systems, the use of project teams and even the transformation from a functional grouping to a marketoriented grouping with interchangeable personnel and equipment.

Structural flexibility can also be external in terms of interorganizational leeway in supporting and sheltering new technologies or developing new products or markets. Examples are various forms of just-in-time (JIT) purchasing, co-makership, co-design, even joint ventures and other co-alignments. By increasing such structural relations with outsiders, the organization can engage more easily in new developments. 
Strategic flexibility. Strategic flexibility or nonroutine steering capacity refers to capabilities related to the goals of the organization or the environment. ${ }^{2}$ This most radical type of flexibility is much more qualitative and involves changes in the nature of organizational activities. Strategic flexibility is necessary when the organization faces unfamiliar changes that have far-reaching consequences and needs to respond quickly. The issues and difficulties relating to strategic flexibility are by definition unstructured and non-routine. The signals and feedback received from the environment tend to be indirect and open to multiple interpretations. Because the organization usually has no specific experience and no routine answer to cope with the changes, management may have to change its game plans, dismantle its current strategies, ${ }^{11}$ apply now technologies or fundamentally renew its products. The response may also be external, e.g. influencing consumers through advertising and promotions, ${ }^{12}$ creating new product markel combinations, ${ }^{10}$ using market power to deter entry and control competitors or engaging in political activities to counteract trade regulations. New values and norms are necessary, and past experience may not provide any advantage. The creation of new activities in new situations may be very important.

Metaflexibility. Besides these three different types of flexibility, we can distinguish the metaflexibility of an organization, i.e. its supporting monitoring or learning system. Metaflexibility involves the processing of information to facilitate the continual adjustment of the composition of management's flexibility mix in line with changes in the environment. This requires the creation, integration and application of flexibility increasing capabilities.

\section{The Organization Design Task: Increasing the Controllability of the Organization}

The ability to initiate the repertoire of managerial capabilities depends on the design adequacy of organizational conditions, such as the organization's lechnology, structure and culture. Those conditions determine the organization's controllability or responsiveness. Designing the appropriate organizational conditions requires identifying the type of technological, structural or cultural changes necessary to ensure effective utilization of managerial capabilities.

Technology. For many service and manufacturing organizations, recent developments in technology have created a range of programmable automation and general information systems that seem to afford much greater flexibility potential. ${ }^{8}$ In this connection, 'technology' refers to the hardware (such as machinery and equipment) and the software (knowledge) used in the transformation of inputs into outputs. The design of technology can range from routine to non-routine, corresponding to the opportunities for routine capabilities. In the last decade, many firms redesigned their technology in order to increase their operational flexibility. For instance, within Philips Semiconductors the implementation of multi-purpose machinery in a large batch or mass mode of production facilitated the possibility of increasing the applicability of machines and of decreasing the set-up times for switching to other products. Consequently, economies of scale could be reached within smaller lot sizes. In addition, the modular production concept gave mass and large batch modes of production the opportunity to combino those economies of scale with increased choice; standard components could be produced in large series, while a variety of products could be assembled through changes in the configuration of components.

Structure. Increases in controllability might also involve changes in organizational structure. Organizational structure comprises not only the actual distribution of responsibilities and authority among the organization's personnel (basic form), but also the planning and control systems and the process regulations of decision-making, coordination and execution. The structural design of the organization can range from mechanistic to organic, ${ }^{13}$ corresponding to the opportunities for structural flexibility. $\Lambda$ functional type of organizing with many hierarchical levels is characteristic of a mechanistic structure. Processes may be highly regulated through elaborate planning and control systems, specialization of tasks and high degrees of formalization and centralization. Only minor incremental changes are possible in such a highly formalized and centralized structure. In contrast, an organic structure can range from the divisionalized form to the project or matrix form consisting of few hierarchical levels. Essential for both the divisional and matrix forms are planning and control systems that are predominantly performance oriented instead of means oriented and allow for ambiguous information and necessary experimentation and intuition. Moreover, direct process regulation in the form of specialization and formalization is extremely low, whereas indirect process regulation by training and education is well developed. Such organic structures provide great leeway for structural flexibility.

Many large corporations are undertaking organizational restructuring to increase their responsiveness. For instance, Xerox was able to exploit its superior technological and market capabilities after fundamentally changing the organizational architecture of the firm by creating business divisions with self-organizing teams and developing new reward and recognition systems. 
Culture. Not only structural changes, but also cultural changes may be necessary to increase the controllability of the firm. Organizational culture can be defined as the set of beliefs and assumptions held relatively commonly throughout the organization and taken for granted by its members. ${ }^{14}$ Essential features of such beliefs are that they are implicit in the minds of organization members and to some extent shared..$^{15}$ The beliefs may constrain managerial capabilities by specifying broad, tacitly understood rules for appropriate action in unspecified contingencies. The organizational culture can range from conservative to innovative, depending on the slack within the current norms and value systems for strategic capabilities.

The beliefs and assumptions of the organizational culture play a central role in the interpretation of environmental stimuli and the configuration of organizationally relevant strategic responses. ${ }^{16}$ Does the organization sce new strategic options? Can it deviate from present patterns? The more innovative the culture, the greater the leeway for strategic flexibility within the organization. Hence, many large corporations such as GE, Philips and ABB have not only restructured the organization, but also tried to change the corporate culture. After downsizing and delayering the company, GE started its famous workout programme, best-practice sessions and change acceleration programme. In the same way, Philips' Centurion programme started with an efficiency drive but was followed by a cultural revitalizing module initiated by the concern committee 'Values and Behaviour (the Philips Way)'. Even more extreme, ABB developed together with its global matrix structure a 21-page 'Mission, Values, and Policy' booklet referred to inside the company as the policy bible.

\section{A Typology of Alternative Flexible Forms}

Our framework in Figure 1 showed that for firms to exploit the flexibility option in turbulent environments they have to solve two challenges: the management challenge and the organization design challenge. This means that management has to activate a sufficient flexibility mix and the organization design must provide adequate potential for flexibility. On the basis of the two central dimensions of organizational flexibility - the extensiveness of the flexibility mix and the controllability of the organizational conditions-we can roughly distinguish four ideal types: the 'rigid', the 'planned', the 'flexible' and the 'chaotic' form ${ }^{17}$ (see Figure 2). Each type represents a particular way of addressing environmental turbulence.

\section{Rigid Form}

The 'rigid form' possesses a very small flexibility mix and the controllability or changeability of the organ- ization is low. The flexibility mix is dominated by simple routines. In addition, the choice and variation possibilities are limited; improvization is a taboo in this organization. The mature technology (routine), the functionalized and centralized structure with many hierarchical layers (mechanistic) together with a monotonous and narrow-minded culture (conservative) do not allow any potential for flexibility and result in a fragile and vulnerable organization.

\section{Planned Form}

The 'planned form' also has a narrow flexibility mix, but the variety of routines and the controllability are less limited than in the 'rigid organization'. The flexibility mix mainly consists of specific rules and detailed procedures which are sophisticated and complex and require an extensive information procossing capacity. Moreover, for every possible change the organization has developed a certain routine.

The rigidity of this organizational form is not a result of the technology or the basic organizational structure, but of strong process regulations such as standardization, formalization and specialization, and very detailed planning and control systems. Also, the shared cultural beliefs and assumptions give very little leeway for deviant interpretations of the environment, and dissonance is potentially threatening the organization's integrity. As long as there are no unexpected changes, the controllability of such an organization is high. However, if changes occur that are not anticipated in the planning repertoire and are threatening the shared idea system, the result is a situation known as 'strategic drift', ${ }^{16}$ in which consciously managed incremental changes do not necessarily keep pace with environmental changes. Inertia sets in and the organization becomes rigid.

\section{Chaotic Form}

The 'chaotic form' has a very extensive flexibility mix dominated by strategic flexibility, but is totally uncontrollable. In such organizations the possibilities for variation are unlimited, because there is no anchorage within the organizational conditions. The innumerable initiatives for change are impossible to implement. A distinct technology, administrative structures and basic shared values stemming from the organizational culture are lacking. Consequently, the environment can directly force the organization into a certain direction; i.e. the organization is controlled by the environment. The lack of administrative stability is caused by 'strategic neglect', which refers to the more or less deliberate tendency not to pay attention to the administrative structure of the organization. As a result, emerging administrative problems deteriorate from petty and trivial to severe and disruptive. The range of possible procedures is so large that making a choice is very difficult and manager's decision-making capacity is greatly 


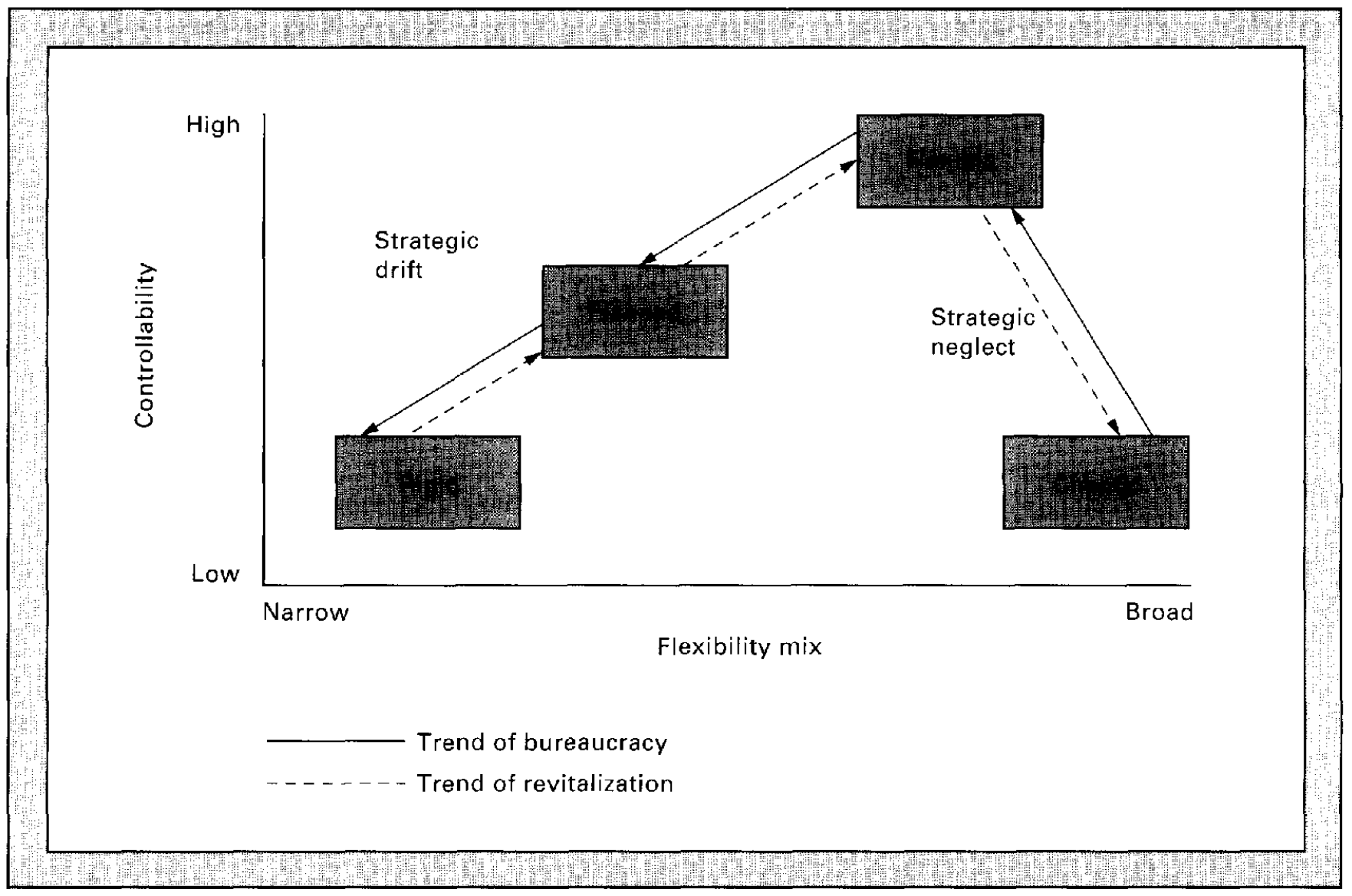

FIGURE 2. Dealing with turbulence.

reduced. ${ }^{4}$ Decisions are delayed although the situation requires immediate action.

\section{Flexible Form}

Finally, the 'flexible form' in the typolngy has a large and rich flexibility mix dominated by strategic and structural flexibility. In addition, the controllability of the organizational conditions is reasonably high. Disturbances are met effectively with alert adaptations without the organization loosing its distinctiveness. Resistance to signals of threat to the idea system is low and the system adapts. Change can be implemented easily through adaptations within the current (non-routine) technology and (organic) structure. The organization is able to resist being overwhelmed by its immediate environment and consequently losing its distinctiveness. It develops some dominance over its environment to preserve its identity. The balance botween change and presorvation is well managed.

\section{Trajectories of Transformation}

The four-cell typology of organizational forms is important for understanding the process of variation in the composition of the flexibility mix and the design of the organizational conditions over time. The typology illustrates that none of the forms is a permanent solution. From this organizational typology, therefore, we can obtain different strategic trajectories of transformation for coping with varying degrees of environmental turbulence.

\section{A Trajectory of Routinization}

In our organizational typology, the process of transition from a chaotic state to a flexible, planned and rigid form can be described as a natural trajectory of routinization. Such a trajectory of routinization (see Figure 3) suggests that starting firms or now ventures operate chaotically in order to develop new capabilities.

Such a chaotic state of loose and unsettled relationships is organic and responds easily to environmental change, but necessarily has slack and is inefficient. ${ }^{18}$ For such an organization, therefore, to 'get off the ground', it must be sufficiently well organized to be lifted from a chaotic state of random, disconnected and uncoordinated impulses. This requires a capacity for achieving some degree of stratcgic focus.

As its dominant environment becomes more and 


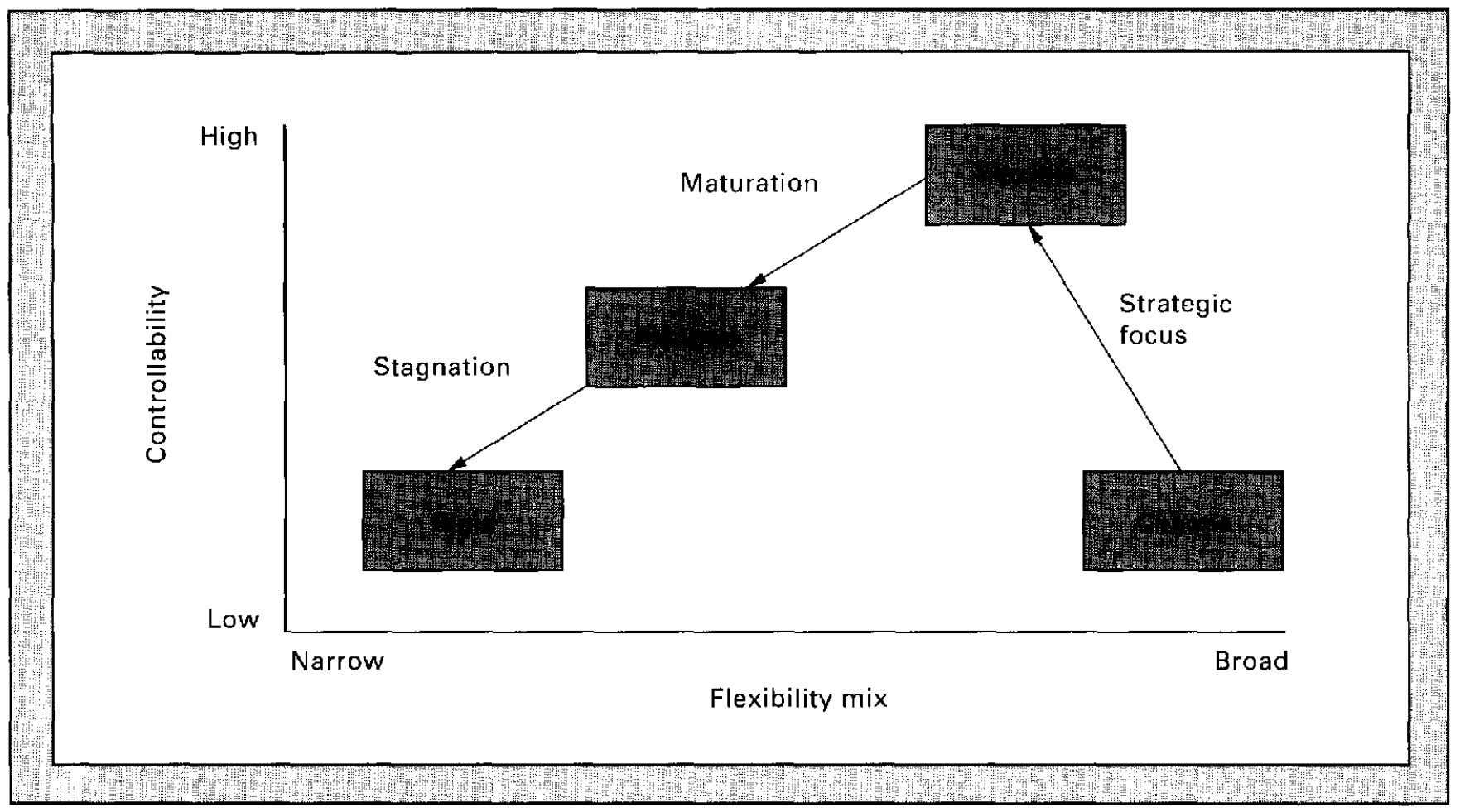

Figure 3. Organizations become more bureaucratic as turbulence decreases.

more predictable, the flexible organization faces a crisis. At this point, it has to become more efficient in its operations in order to be able to extract greater benefit from the changes that it introduced previously. The organization needs to be transformed in a manner which best pormits it to exploit the existing knowledge and opportunities. This transition from a flexible towards a planned form can be portrayed as a process of maturation. Maturation requires a greater need to professionalize and institutionalize the intelligence-gathering and information-processing function and to integrate the efforts of decision makers by formal means ${ }^{19}$ (process regulations). At this stage, therefore, the organization needs to be able to intensify its metaflexibility appropriately, so as to improve its capacity to plan, monitor and control the situation, and to implement decisions and procedures which would help to reduce the level of environmental turbulence.

Nonetheless, in the process of adapting and refining the organizational conditions in order to exploit time and response opportunities efficiently, the 'planned' organization runs the risk of losing its strategic and structural flexibility as it concentrates increasingly upon the accumulation of a large number and variety of operational procedures and routines (operational flexibility). In these circumstances it becomes progressively rigid. In this process toward stagnation, the routinization and systematization of organizational conditions bring bureaucratic momentum, traditions and resistance to change. These all play an important role in boosting conservatism. As a result, the rigid form is characterized by a reduced emphasis on product-market innovation, risk taking and proactiveness. The rigid form has pursued the evolution of its development to the extreme at the cost of decreased flexibility and innovative capacity.

\section{The Reverse Trajectory of Revitalization}

For many organizations, indeed, the transition from chaotic state towards a 'rigid' organization may be regarded as a 'natural trajectory' or life cycle. However, a transition in the reverse direction may, in our typology, also be porceived as a trajectory, although it may not be as easy to achieve or scem as 'natural' as the former process (sce Figure 4). Many large corporations like GE, IBM and Philips realized years ago that they had gone too far with such a process of routinization and had become extremely rigid organizations. I'hey wanted to revitalize the company into a more flexible or even chaotic form. Some observers argue that older, larger corporations must die off, likc dinosaurs, to be succeeded by a new breed better adapted to its environment, in much the same way that has characterized biological evolution. In contrast with such a naive selection perspective, researchers like Kanter ${ }^{20}$ and Baden-Fuller and Stopford ${ }^{21}$ showed that mature corporations can mould themselves into flexible forms that balance corporate discipline with entrepreneurial creativity. However, 


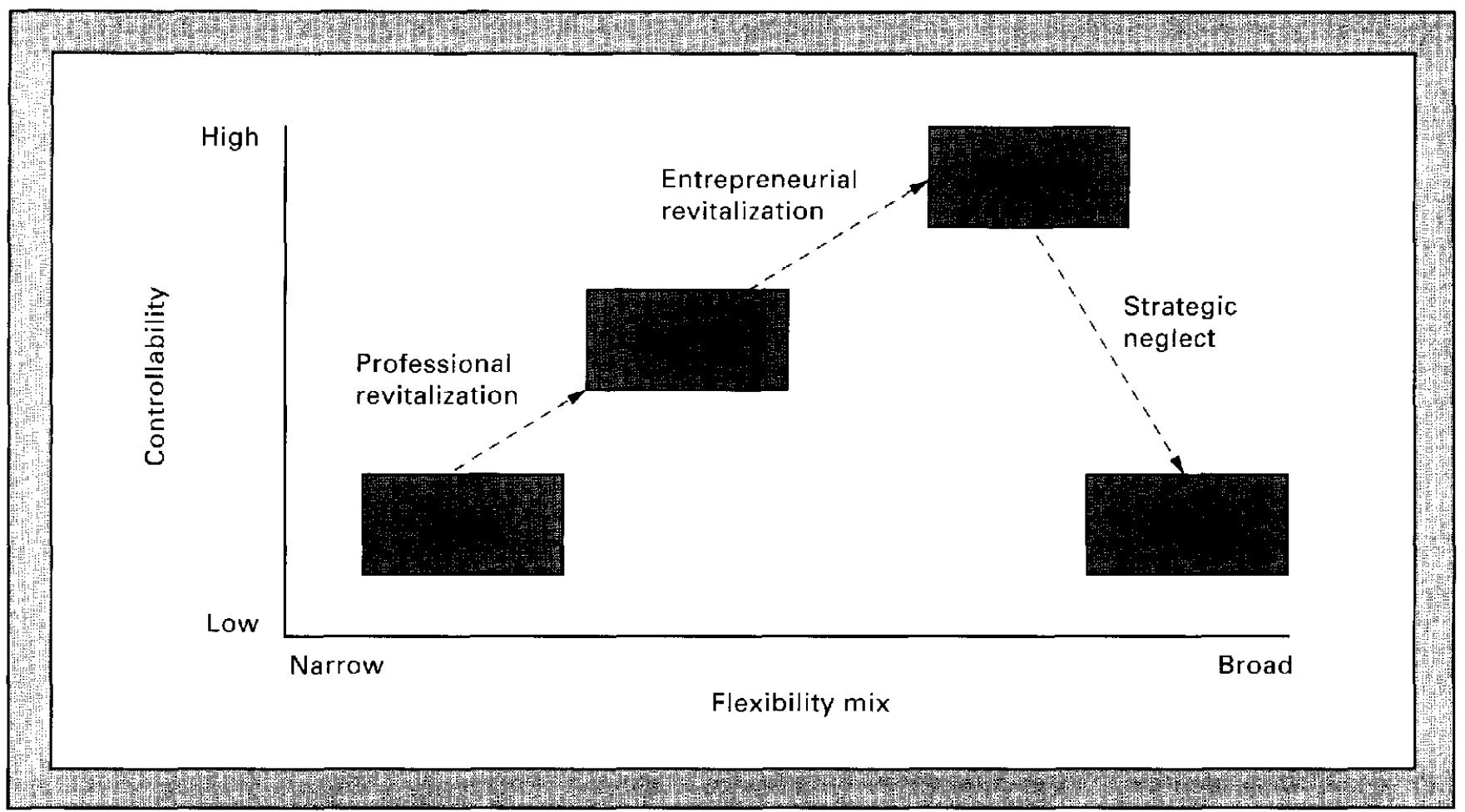

Figune 4, Organizations revitalize as turbulence increases.

they argue that rebuilding a mature organization takes time and that firms must avoid quick fixes. In fact, there are many routes mature corporations might take. On the hasis of our organizational typology, we will provide a more systematic mothod for supporting management efforts directed towards 'revitalization' of maturs or declining organizations. Such trajectories are most likely to be effective under extremely turbulent environments.

\section{The FAR Method in Practice}

The FAR inethod provides the practitioner with instructions for systematically describing, analysing and assessing the required flexibility derived from the level of environmental turbulence, management's actual flexibility mix and the responsiveness of the organization in terms of our typology (see Figure 5). Moreover, the method supports the consultant in deriving recommendations for redesigning the organization in order to reduce the gap between required and actual flexibility. In the various phases of the process of revitalization, the FAR method poses the following questions:

Orientation: What is the point of departure of the organizational unit (strategic group, stakeholders analysis, adequacy of flexibility label, boundary decisions, history)?
Analysis: What are the inputs, throughputs and outputs of the organizational unit and which external clements or constituents are important for attaining these inputs and disposing of the outputs (specification of primary process)?

How flexible does the organizational unit have to be (desired state depending on the degree of environmental turbulencc)? How flexible is the organization at the moment (current state depending on the actual flexibility mix and flexibility potential within the organizational conditions)?

Assessment: Is there a gap between the required flexibility mix and the actual flexibility mix (discrepancy analysis)?

If so, what are the relevant flexibility aspects types of flexibility and required information activities?

Redesign: How should a more flexible organization be redesigned?

What are possible design variables for improving the flexibility potential of the organization (technological, structural and/or cultural design variables)?

What steps have to be taken (strategic trajectories of change)?

What persons and resources should be involved and at what time?

In order to test the method, it was applied in three different organization units operating in different, changing environments: an administrative unit $\mathrm{X}$ of the Dutch Postbank, a production unit Y of Philips 


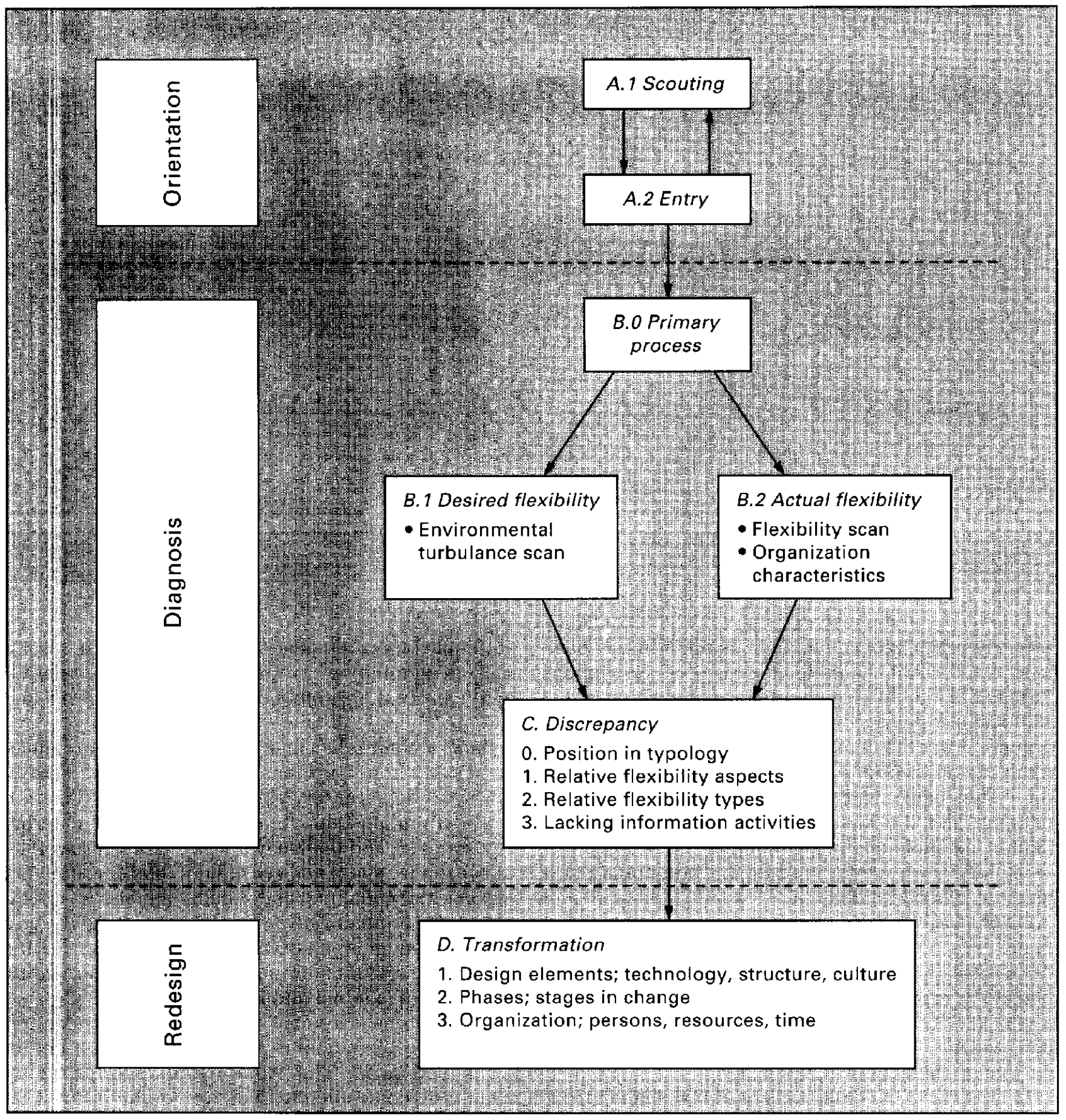

Ficune 5 . Flexibility audit and redesign.

Semiconductors and an R \& D unit Z of the Dutch Gas Company. ${ }^{22}$ In each of these cases there was a clear need for flexibility due to a shift in the level of environmontal turbulence. In each case we conducted pre-measurements of the level of environmental turbulence, the flexibility potential within the organizational conditions and the composition of the flexibility mix. These pre-measurements allowed us to generate advice concerning effective strategic tra- jectories of revitalization. After 1 year we conducted a post-measurement in order to validate the recommendations of the FAR method (see Figure 6).

\section{The Dutch Postbank: Professional}

Revitalization of Department $X$

This trajectory was found within the Administrative Department X of the Dutch National Postbank, the fifth largest bank of The Netherlands. The bank was 


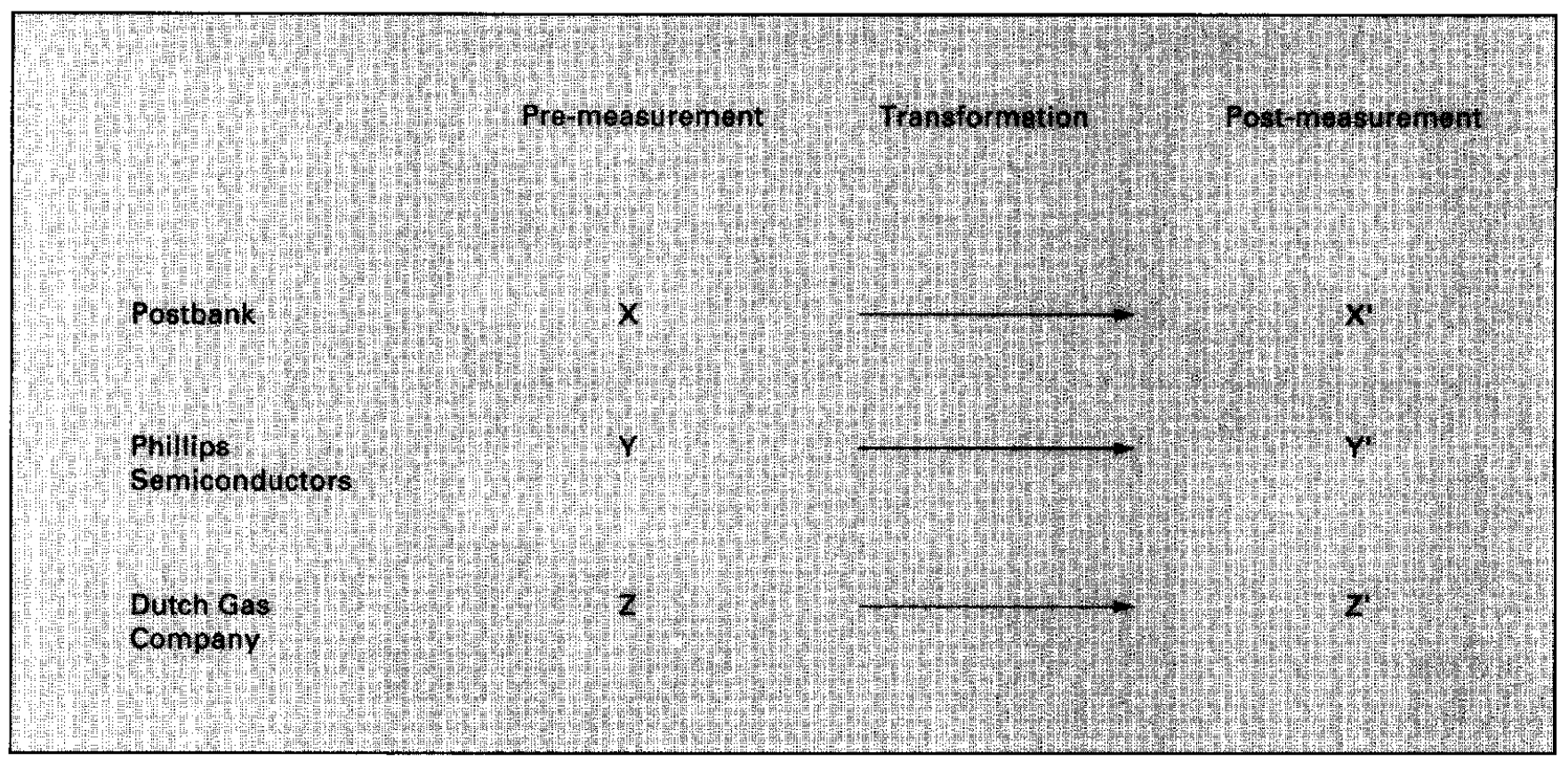

Figune 6. Testing the approach.

recently privatized. In the past, its main line of business was retail banking because of restrictions imposed by the Dutch government. It largely provided standardized services to more than 6 million account holders. After the deregulation it intended to provide more customized services as a part of corporate banking. The bank was confronted with increasing national and international competition, new information technologies in banking, an increased pressure on interest margins and the introduction of new banking-related services.

On the basis of results of the pre-measurement, we found that Administrative Department Corporate Accounts of the Dutch Postbank had hardly any flexibility mix and possessed a routine technology, a very mechanistic structure and, to some extent, a conservative culture. Department $\mathrm{X}$ corresponded with the rigid form in our typology.

Nonetheless, the environmental turbulence profile showed that the environment of the department was no longer stable, but highly complex and dynamic, especially regarding the composition of the workload, developments in information technologies and specific requirements of clients. According to our typology, this shift in environmental turbulence, which is largely predictable, requires a more comprehensive flexibility mix dominated by operational flexibility together with a more non-routine technology. Management must activate many sophisticated routines to deal with these dynamic and complex changes. To facilitate such routine proliferation, the management of Department $\mathrm{X}$ needs a more extensive information processing capacity to anticipate complex changes. This Iransition from a rigid to a more planned organization can be referred to as a process of professional revitalization (see Figure 7).

Such a comprehensive and often dramatic movement away from traditions, conservatism and rigidity towards adaptiveness, vigilance and diversification could stimulate Department $\mathrm{X}$ to track the external environment and to discover new market forces. The transition we suggested could help the department to become more adaptive and sensitive to market forces, to vary its product line and volume more easily, and to become more aggressive and innovative in dealing with new services and more imaginative in meeting the needs of external and internal clients.

The post-measurement shows that a strategic trajectory of professional revitalization had resulted in a planned form. The Administrative Departmont, which was confronted with increasing environmental dynamism and complexity, was able to activate operational short-term volume and mix flexibility originating from a more non-routine technology and a less mechanistic organizational form. Nonetheless, as a consequence of a lack of preservation in its culture, this increased potential could not be utilized optimally. The transmission of appropriate core values by socialization was not sufficiently worked out by management.

\section{Philips Semiconductors: Entrepreneurial Revitalization of Assembly Department $Y$} This transition was found within Philips Semiconductor's' Assembly Department Glass-Bead 


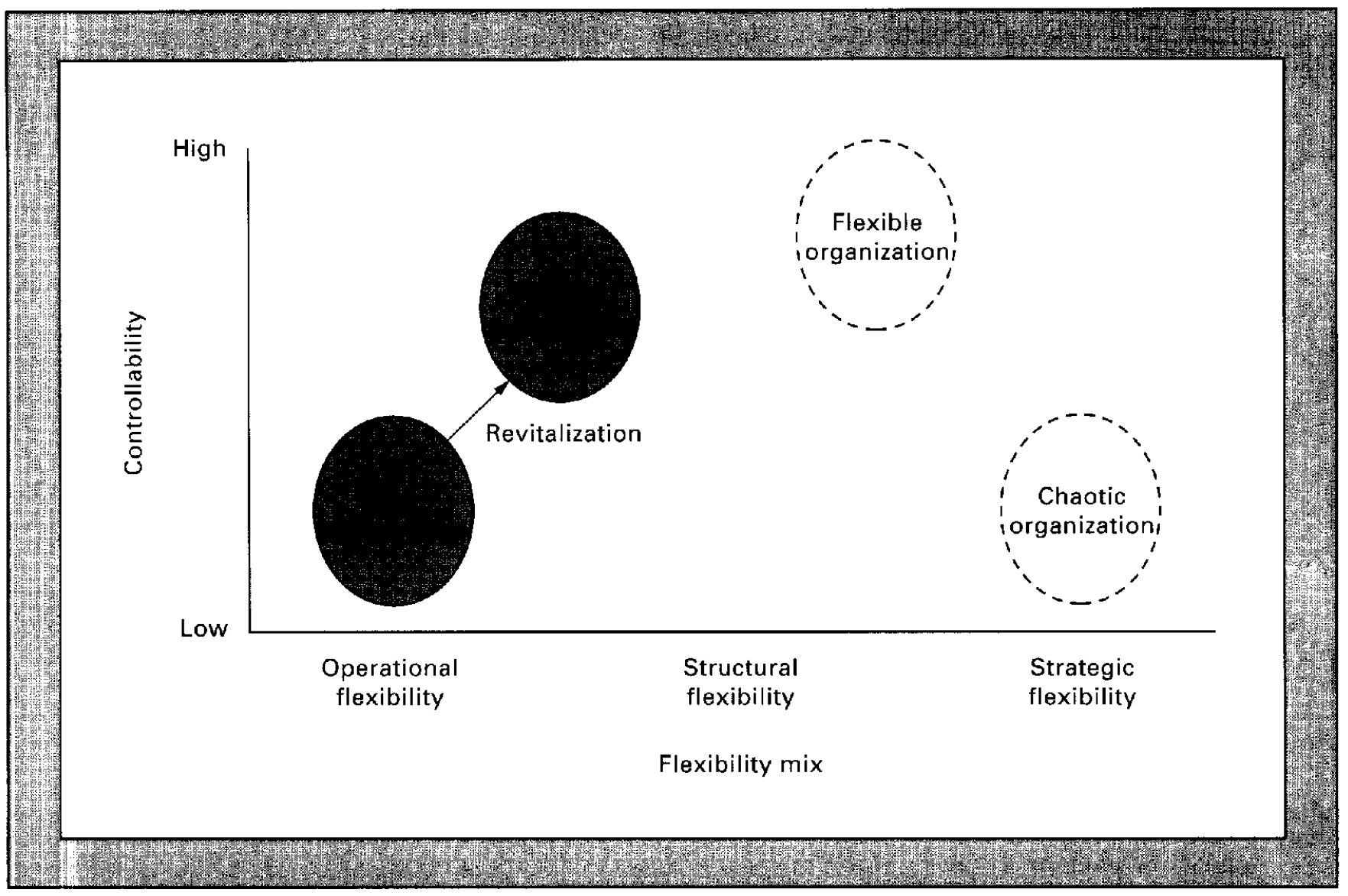

Ficune 7. Postbank revitalization of the administration.

Diodes, which was professionally organized within the product line Medium Power Rectifiers and Stacks for a reasonably turbulent environment (dynamic, complex but largely predictable). The Department employed an extensive flexibility mix, dominated by operational flexibility, and possessed a more non-routine technology, a mechanistic structure and a conservative culture. Also, we found highly developed intelligence systems as a part of the metaflexibility and many structural process regulations meant to facilitate the development of routines. However, due to the partial implementation of a large Technology Redesign Project, the technology was not as non-routine as we had predicted. Consequently, the departmont still had problems activating operational flexibility and did not totally correspond with the planned configuration, but was positioned somewhere between the rigid and planned form in our typology (see Figure 8).

Furthermore, the environmental turbulence profile showed that the environment of Assembly Department $\mathrm{Y}$ was no longer only complex and dynamic, but also unpredictable, especially regarding the developments in outer technologies (introduction of plastic diodes, release of higher-voltages versions, new crystal types and the advance of integrated circuits in the application markets) and product-market combinations (PMCs) (price erosion and unforeseen volume developments). In this connection, pure anticipation in terms of routine proliferation is insufficient. A strong commitment to a likely future may even reduce the assembly department's receptiveness to change. Instead of further increasing its information-processing capacity, management should reduce the need for information processing and develop structural and strategic flexibility. This transition from a merely planned form to a more flexible form is referred to as a trajectory of entrepreneurial revitalization.

The planned configuration is seriously handicapped when confronted with fundamentally unpredictable environments. A trajectory of entreprencurial revitalization could help the Assembly Department to exploit more easily unknown opportunities in technologies and PMCs. In addition, the department still needed operational flexibility for short-term fluctuations in demand. Moreover, the sensor and information-processing 


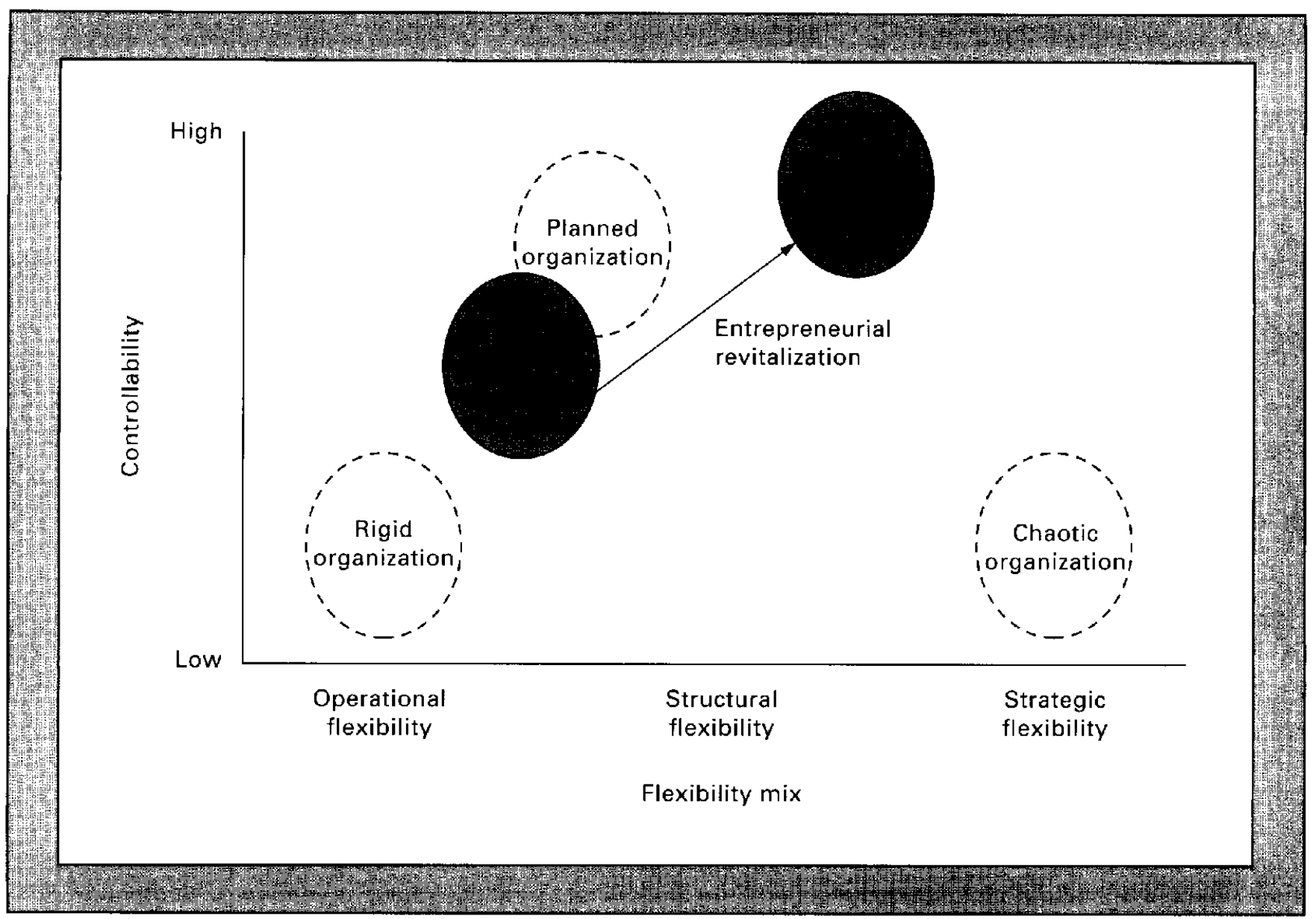

Fioure 8. Philips semiconduotors revitalization of assombly.

capacity would have to be very rudimentary for strategic flexibility and directed towards enhancing the receptiveness to new environments.

The results of the post-measurement show that this trajectory of entrepreneurial revitalization resulted in a hybrid of a planned/flexible form. This transition of entrepreneurial revitalization was accomplished by radically transforming the firm from a bureaucratic, conservative company to one that is innovative and responsive. The development of autonomous task groups, interdisciplinary marketing-productiondevelopment teams, less formal planning and control together with the development of a unique logo for the plant, the organization of social events, special training and a news bulletin for employees made this transformation possible.

\section{The Dutch National Gas Company: Strategic Focusing of $R \& D$ Department $Z$}

If the organization is successful in achieving a major transformation, it faces the opposite danger of 'overshooting' its target and becoming 'chaotic'. 'This possibility arises from the danger of strategic neglect, i.e. the failure to retain the necessary strategic focus and the conditions which will enable the company to organize itsolf sufficiently to create and/or to implement radical innovations. To exemplify, within the Dutch National Gas Corporation, we found that the R \& D Department functioned in an increasingly complex, dynamic and unpredictable environment and possessed a very non-routine technology and an extremely innovative culture. Also, the department's information-processing capacity was very rudimentary. Nonetheless, the department's structure was less organic than we had expected, due to the splitting up of managemont tasks, many hiorarchical levels, long horizontal chains and strict planning systems. Furthermore, compared to the enormous potential for strategic flexibility, this was not as high as we had estimated. Especially, the initiation of new research programmes which required cross-sectional projects was problematic for the department.

The R \& D Department did not correspond with the flexible form, but could be characterized better as a chaotic form in our organizational typology (see Figure 9). There was an unlimited potential for flexi- 


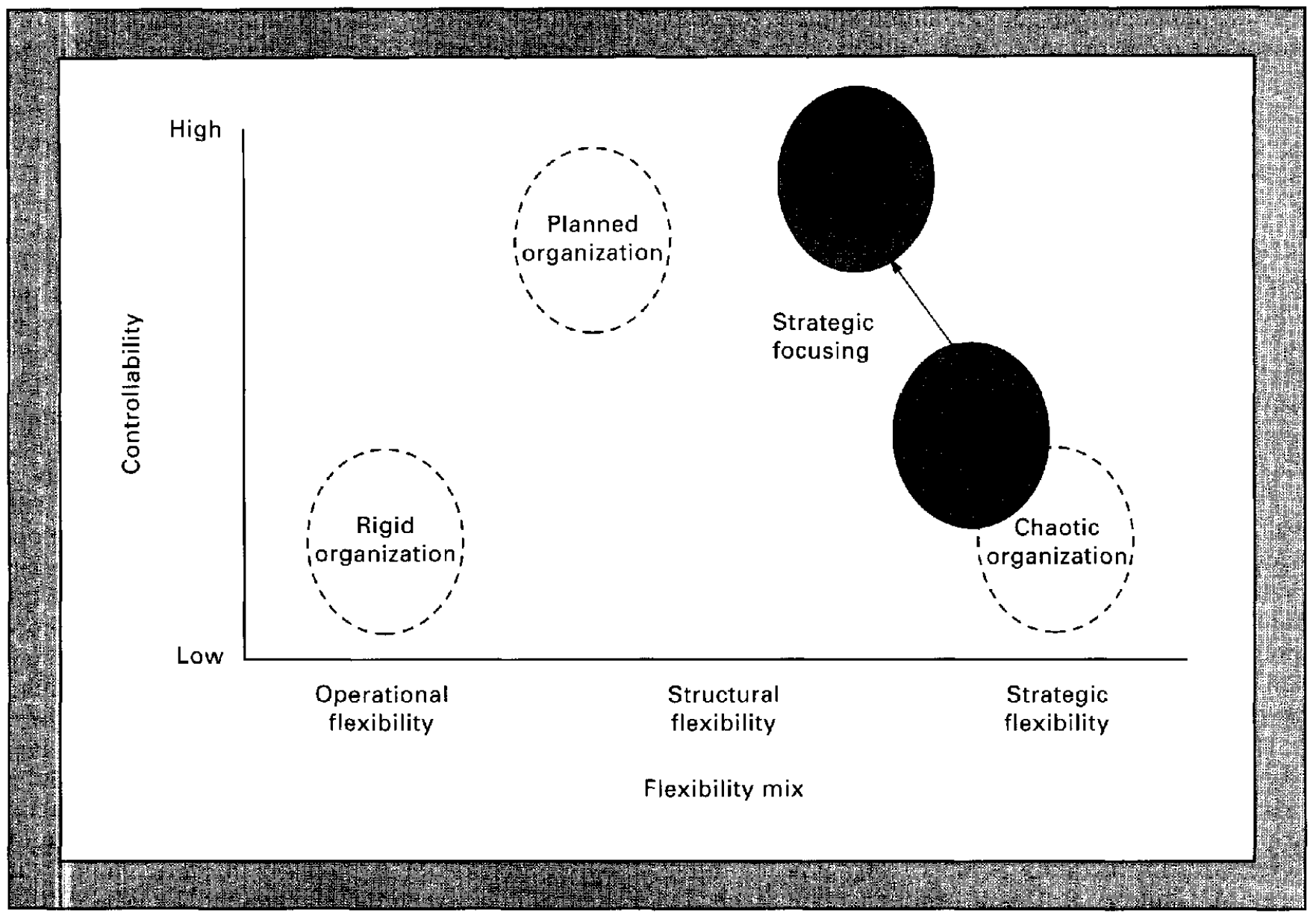

Fituke 9 , The Dutch Cas Compony strategla focusing of R $\&$ D.

bility, but it was impossible for management to activate this potential due to the lack of preservation in its culture. In other words, the department was too flexible. There were many initiatives for new research but they could not be implemented because there were no clear administrative structures and 'shared values'. Nor did the department have adequate information regarding man-hours, costs and technical progress per project. The schizophrenia of the department resulted in distorted information on the basis of which management could not make appropriate decisions. This strategic neglect, or the ignorance of administrative structures and a shared culture together with the opportunistic behaviour of individual researchers resulted in a lack of decisiveness regarding research priorities, a fragmented structure and a loose constellation of various subcultures.

According to our organizational typology, to lift this organization from a chaotic state of random, disconnected and uncoordinated impulses towards a more flexible configuration, a trajectory of strategic focusing is required (see Figure 9). This strategic focusing may be manifested in preserving a higher- order core culture and establishing clearer administrative structures. Furthermore, to activate the appropriate flexibility-increasing procedures, management would have to conduct more informationscanning as a part of the metaflexibility.

Our post-measurement showed that the originally chaotic research department was able to activate a broader flexibility mix dominated by structural flexibility and strategic programme flexibility originating from a clearer organic structure and a stronger preservation of the department's core culture. In order to preserve an adequate flexibility potential within Research Department Z, management had started various social events to create a higher-order core culture. Also, academics had to stay in the research department at least 3 years in order to strengthen some shared values and a common history. In addition, managers gave more attention to their leadership style. They provided more direction and feedback (institutional leadership). By emphasizing a commonly shared management and organization philosophy, the distinction between the formal and actual organization was reduced. This overlapping 
culture enhanced the potential for flexibility, but also corrected opposing initiatives.

\section{Conclusions}

In this article we explored the flexibility option in situations of high environmental turbulence. We argued that flexibility is a managerial as well as an organization design task. These two dimensions allowed us to construct a rich typology of organizational forms for coping with changing levels of environmental turbulence. Furthermore, from this typology different trajectories of transformation could be obtained.

Some likely trajectories were considered with examples based on flexibility audits in Philips Semiconductors, the Dutch Postbank and the Dutch National Gas Corporation. At the moment, the FAR method has been applied in several other large corporations in various industries, o.g. KLM Royal Airlines, the Dutch PTT, Dutch Van Ommeren Tank Storage and Ericsson.

On the basis of these flexibility audits, we may conclude that in reasonably stable environments in which firms' attention is directed lowards reducing the level of environmental turbulence, a natural trajectory of routinization is most likely (the planning option). Contrary to this evolutionary approach, in extremely turbulent environments in which firms are confronted with unpredictable changes, a trajectory of revitalization is more likely to be successful (the flexibility option).

Of course, we have to realize that both trajectories have their pitfalls. The risk of a trajectory of routinization is the transformation of the firm into a rigid form as a result of strategic drift. The surplus of operational flexibility, consisting of sophisticated routines, creates inertia in the form of a very mechanistic structure and a very narrowly focused culture. The growing resistance to 'deviant' interpretations of the environment reflects a tendency toward 'overbalance' of the rigid form. On the other hand, the risk of a trajectory of revitalization is turning into a 'chaotic form' as a result of 'strategic neglect'. The surplus of structural and strategic flexibility leads to unfocused actions with disconstructive results. The lack of administrative structures, sense of direction, shared beliefs and institutional leadership is characteristic of a tendency towards 'underbalance' of the chaotic form. Our organizational typology therefore highlights two sets of transition. First, to become successful in turbulent environments, an organization has to rise from a state of initial chaos or disorganization. Second, to remain successful, organizations have to manage a cyclical process which requires them to transform themselves from a 'planned' form into a 'flexible' form, and then back from a 'flexible' form into a 'planned' form, to match the opportunities set by the changes in the level of turbulence over time.

\section{References}

1. H. Mintzberg, Strategy formation: schools of thought, In J. W. Frederickson (Ed.), Perspectives on Strategic Management, pp. 107-208, Harper \& Row, New York (1990).

2. D. A. Aaker and B. Mascarenhas, The need for strategic flexibility, Journal of Business Strategy 5 (2), 74-82 (1984).

3. H. I. Ansoff, Corporate Strategy, McGraw-Hill, New York (1965).

4. D. J. Eppink, Planning for strategic flexibility, Long Range Planning 11 (4), 9-15 (1978).

5. J. B. Quinn, Strategies for Change-Logical Incrementalism, Irwin, Homewood, IL (1980).

6. H. I. Ansoff, The Changing Shape of the Strategic Problem, In D. E. Schendel and C. W. Hofer (Eds), Strategic Management: a New View of Business Policy and Planning, pp. 30-44, Little, Brown \& Co., Boston/Toronto (1978).

7. T. De Leeuw and H.W. Volberda, On the concept of flexibility: a dual control perspective, Omega 24 (2), (1996).

8. P. S. Adler, Managing flexible automation, California Management Review 30 (3), 34-56 (1988).

9. J. B. Quinn, Managing innovation: controlled chaos, Harvard Business Review 63 (3), 7884 (1985).

10. H. G. Krijnen, The flexible firm, Long Range Planning 12 (2), 63-75 (1979).

11. K. R. Harrigan, Strategic Flexibility, Lexington Books, Lexington, MA (1985).

12. B. Mascarenhas, Coping with uncertainty in international business, Journal of International Business Studies 13 (2), 87-98(1982).

13. T. Burns and G. M. Stalker, The Management of Innovation, Tavistock, London (1961).

14. P. Bate, The impact of organizational culture on approaches to organizational problemsolving, Organization Studies 5 (1), 43-66 (1984).

Building Flexible Organizations for Fast-moving Markets 
15. G. Hofstede, Motivation, leadership and organization: do American theories apply abroad?, Organizational Dynamics 9 (1), 42-63 (1980).

16. G. Johnson, Strategic Change and the Management Process, Basil Blackwell, Oxford (1987).

17. H. W. Volberda, Toward the flexible form: how to remain vital in hypercompetitive environments, Organization Science 7 (4), 359-374 (1996).

18. J. M. Utterback and W. J. Abernathy, A dynamic model of process and product innovation, Omega 3 (6), 639-656 (1975).

19. D. Miller and P. Friesen, Archetypes of organizational transition, Administrative Science Quarterly 25 (2), 268-300 (1980).

20. R. M. Kanter, When Giants Learn to Dance: Mastering the Challenge of Strategy, Management and Careers in the 1990s, Simon \& Schuster, New York (1989).

21. C. Baden-Fuller and J. M. Stopford, Rejuvenating the Mature Business, Harvard Business School Press, Boston, MA (1994).

22. H. W. Volberda, Organizational Flexibility: Change and Preservation-a Flexibility Audit and Redesign Method, Wolters-Noordhoff, Groningen (1992).

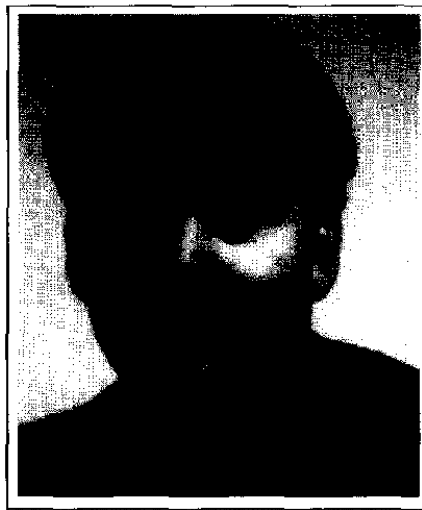

Dr Henk W. Volberda is Associate Professor of Strategic Management at the Rotterdam School of Management, Erasmus University, The Netherlands. 


\title{
page 169 Building Flexible Organizations for Fast-moving Markets
}

\author{
Henk W. Volberda
}

Organizational flexibility is seen as a strategic option when anticipation is impossible and surprise is likely. Flexibility is a function of the interaction of two sets of variables. It is both a managerial and an organization design task. It has to be concerned with creating or stimulating the organizations's control capacity. To do this it needs to provide rapid response to changes that are familiar, to ensure that management can adapt decision-making within a given structure and at the same time to respond quickly when faced with unfamiliar changes that have farreaching consequences. And the organization's supporting learning system has to be able continually to adjust in tune with changes in its environment.

The organization's technology, structure and culture will, of course, affect its responsiveness. Increases in controllability can also involve changes in organizational structure. Xerox, for example, was able to exploit its superior technological and market capabilities once it had fundamentally redesigned its organizational architecture. Other organizations such as GE, Philips and ABB have not only restructured the organization but also tried to change the corporate culture.

On the basis of the two central dimensions of organizational flexibility, four ways of addressing change can be identified. The 'rigid form' is dominated by simple routines and the result is a fragile and vulnerable organization. The 'planned form' has a narrow flexibility mix and, if changes occur, the result can lead to inertia and a rigid organization. Where there is 'chaotic form' the possibilities for variations are unlimited but decisions are delayed even though the situation demands immediate action. The 'flexible form' has a large and rich flexibility mix dominated by strategic and structural flexibility. The balance between change and preservation is well managed. The process of transition from a chaotic to a flexible, planned and rigid form can be described as a trajectory of routinization moving from chaos through strategic focus to maturation which can lead to stagnation. It is possible to move in the reverse direction, as is shown by the histories of IBM and Philips.

The Flexibility Audit and Redesign (FAR) method provides a useful means of analysing and assessing the need for the level of flexibility needed by an organization to cope with changes in the environment. The FAR method uses questions on orientation, need, discrepancy and the redesign required and has been tested in the different organizations in different changing environments. In one case, that of an admin department of the Dutch National Postbank, the solution was 'professional revitalization'. At Philips Semiconductors, the result was a hybrid of a planned/flexible form and the Dutch National Gas Company was able to enhance the potential for flexibility.

The trajectories do have pitfalls. However, to become successful in a turbulent environment, the organization needs to move from chaos. It then has to manage a cyclical process from planned form to flexible form and back. This will enable it to exploit the opportunities which exist.

\section{page $184 \quad$ Green Alliances: Building New Business with Environmental Groups}

\section{Cathy L. Hartman and Edwin R. Stafford}

Market-based environmentalism (MBE) has an objective to create market incentives that make ecology strategically attractive to businesses. As many firms do not have environmental expertise, joining forces with environmental pressure groups can be a viable green strategy. For environmentalists, green alliances can be more effective 